\title{
Ação política e produção de subjetividade: a herança de terra, trabalho e participação política na produção de um éthos agricultora
}

Rita de Cássia Maciazeki-Gomes. Universidade Federal do Rio Grande Maria Juracy Filgueiras Toneli. Universidade Federal de Santa Catarina Conceição Nogueira. Universidade do Porto

Rita Grave. Universidade do Porto

\section{Resumo}

Ancorado nos estudos de gênero e modos de subjetivação, este estudo analisa as intersecções entre ação política e subjetividade na produção de um éthos agricultora. O estudo contempla o mapeamento e a análise das narrativas de mulheres trabalhadoras rurais sobre os efeitos das experiências associadas aos espaços da casa, da propriedade e do movimento social. As análises produzidas expressam saberes e práticas ligadas às trajetórias de vida das mulheres na agricultura familiar, marcadas pela herança de terra, trabalho e participação política. A herança transmitida, de geração em geração, reporta a problematizações acerca das posições historicamente ocupadas pelas mulheres nas relações familiares e de trabalho. A participação no movimento social de mulheres rurais contribui para a produção de estratégias de resistência e criação, uma vez que potencializa a abertura de modos de vida outros, para além daqueles associados às atribuições normativas de gênero.

Palavras-chave: gênero; trabalhadoras rurais; movimentos sociais; participação comunitária; produção de subjetividade.

\begin{abstract}
Political action and production of subjectivity: the inheritance of land, labor and political participation in the production of a farmer ethos. Anchored in gender studies and modes of subjectivation, this study analyzes the intersections between politic action and the subjectivity in the production of a farmer ethos. The study contemplates the mapping and analysis of female rural workers narratives about their experiences in the spaces of the house, property and social movement. The analysis express knowledge and practices related to the life trajectories of women in family agriculture, marked by land inheritance, work and political participation. The transmitted inheritance, from generation to generation, reports to the problematizations about the positions historically occupied by women in family and work relations. Participation in the social movement of rural women contributes to the production of strategies of resistance and creation, since it potentiates the opening of other ways of life, in addition to those associated with normative gender attributions.
\end{abstract} Keywords: gender; female rural workers; social movements; community participation; production of subjectivity.

\section{Resumen}

Acción politíca y producción de subjetividad: a la herencia de la tierra, trabajo y participación política en la producción de un éthos agricultora. Anclado en los estudios de género y modos de subjetivación, este estudio analiza las intersecciones entre la acción política y la subjetividad en la producción de un ethos agricultora. El estudio contempla el mapeo y análisis de las narrativas de las trabajadoras rurales sobre los efectos de las experiencias asociadas con los espacios de la casa, de la propiedad y del movimiento social. Los análisis expresan conocimientos y prácticas relacionados con las trayectorias de vida de las mujeres en la agricultura familiar, caracterizadas por la herencia de tierras, el trabajo y la participación política. La herencia transmitida, de generación en generación, informa sobre las problematizaciones sobre los cargos que históricamente ocupan las mujeres en las relaciones familiares y laborales. La participación en el movimiento social de mujeres rurales contribuye a la producción de estrategias de resistencia y creación, ya que potencia la apertura de otras formas de vida, además de aquellas asociadas con las atribuciones normativas de género.

Palabras clave: género; mujeres trabajadoras rurales; movimientos sociales; participación comunitaria; producción de subjetividad. 
As reflexões apresentadas neste estudo são um recorte de uma tese de doutorado que analisou os efeitos da ação política na produção de subjetividade de mulheres trabalhadoras rurais, participantes do movimento social do campo, da região noroeste do Estado do Rio Grande do Sul (RS), Brasil (Maciazeki-Gomes, 2017). As discussões levantadas produziram um campo de problemas da subjetividade (Fernández, 2008), na articulação entre gênero, política e produção de subjetividade. Gênero associado a uma rede de saberes e práticas, aos modos de se fazer gênero (Butler, 1998, 2015), como experiência de si, efeito das relações sociais e institucionais, econômicas, históricas e políticas, tomado numa perspectiva interseccional (Nogueira, 2013). Política entendida como uma ação política, como uma prática ética expressa na relação consigo mesmo e na relação com os outros (Maciazeki-Gomes, 2017), numa posição intersubjetiva (Ortega, 1999). Nesta perspectiva, a ação política é parte constitutiva de um éthos (Foucault, 2012b), irradiadora de práticas associadas a multiplicidade, a diferença e a singularidade. Os efeitos dessas experiências, atravessadas por redes de saber e poder acionam e produzem subjetividades (Foucault, 2012d).

Ancorado nos estudos de gênero e modos de subjetivação, este estudo analisa as intersecções entre ação política e subjetividade na produção de um éthos agricultora. $\mathrm{O}$ estudo contempla o mapeamento e a análise das narrativas de mulheres trabalhadoras rurais sobre os efeitos das experiências ligadas aos espaços da casa, da propriedade e do movimento social. As narrativas expressam intersecções entre os saberes e as práticas associadas a agricultura familiar na região noroeste do Estado do RS do Brasil e a participação política no movimento social de mulheres trabalhadoras rurais.

As intersecções entre gênero, política e subjetivação compuseram um campo de problemas que possibilitou o acompanhamento e as análises das narrativas das trajetórias de vida associadas a uma herança de terra, trabalho e participação política. A herança está imbricada às especificidades da agricultura familiar no sul do Brasil, aos atravessamentos éticos/morais herdados de uma cultura advinda da colonização alemã e do processo de participação política, tanto no âmbito familiar, nas relações afetivo-familiares e conjugais, como também laborais. A compreensão da temática da herança passou pelo mapeamento dos processos de socialização e subjetivação que imprimem práticas de governamentalidade (Foucault, 2012a).
$\mathrm{Na}$ agricultura familiar, a herança pode ser associada à sucessão rural, logo ao comando da unidade produtiva. A propriedade, composta pela casa e a unidade produtiva, constitui um espaço onde são estabelecidos laços afetivos, familiares e também laborais que provem o sustento da família. Neste território é comum encontrar a convivência de três gerações de uma mesma família.

Se por um lado, a ideia de herança evoca a posse de bens materiais da família, por outro, dá acesso a um legado moral formado por tradições, costumes, valores, regras e normativas pertencentes a um determinado círculo familiar. A herança, neste contexto, remete a um regime de verdades, a práticas discursivas que, ao serem repassadas de geração em geração, acionam e produzem processos de subjetivação ligados à agricultura familiar no sul do Brasil. Não se trata de uma transmissão homogênea e atemporal. Ao contrário, a herança cultural da família é atravessada pelas questões do seu tempo, resultado de continuidades e rupturas em relação aos modos de pensar, sentir e viver a vida, em sua singularidade. Deste modo, o exercício analítico procurou problematizar as continuidades e rupturas, priorizou as implicações relacionais em detrimento dos aspectos cronológicos. Levou em conta o mapeamento da presença de "um habitus familiar e histórico sempre em transformação, contestado e reafirmado, que dá dimensões concretas para a ação e a significação na relação entre família e gerações" (Scott, 2010, p. 252).

As análises das narrativas associadas a esse habitus familiar problematizam a herança imersa às práticas e seus efeitos nos modos de conduzir a vida, de se relacionar consigo e com os outros, associado a um éthos agricultora. Para Foucault (2013, p. 264), o conceito grego de éthos se relaciona com "a maneira de ser e de se conduzir" ligada aos "hábitos, maneira de caminhar... comportamento diante da vida". Um éthos agricultora se constitui como um dispositivo analisador das práticas que expressam as condições de possibilidade de se tornar o que se é. Para Castro (2016) o conceito de éthos está associado a uma crítica experimental que Foucault utiliza como uma aposta que se operacionaliza em três partes: a homogeneidade, a sistematicidade e a generalidade. A homogeneidade dimensiona as práticas como objeto de estudo; a sistematicidade leva em conta os três domínios das práticas, ou seja, "as relações de domínios sobre as coisas (saber), das relações de ações com outros (poder), as relações consigo mesmo (ética)" (Castro, 2016, pp. 154-155); e a generalidade: demarca o caráter recorrente das práticas. 
A ideia de éthos agricultora dialoga com os pressupostos genealógicos de Foucault (1979/1995) na composição de análises perpassadas pela contingência histórica, associada as condições de possibilidade das práticas que resultaram naquilo que somos hoje. As narrativas estão imersas as especificidades dos modos de vida das mulheres em contextos rurais (Maciazeki-Gomes, Nogueira, \& Toneli, 2016), do cenário da agricultura familiar e dos atravessamentos da ação política.

Tendo presente essa rede de problematizações, este estudo analisa as intersecções entre ação política e subjetividade na produção de um éthos agricultora. Para tanto, levou em conta o mapeamento e a análise das narrativas dos efeitos das experiências das mulheres trabalhadoras rurais relacionadas com a herança de terra, trabalho e participação política, sendo acompanhadas pelas práticas imersas nos espaços da casa, da propriedade e do movimento social.

\section{Estratégias metodológicas}

Inspirado na abordagem genealógica de Michel Foucault (1979/1995), o percurso metodológico tomou a escuta, o registro e a análise das narrativas das experiências relacionadas à agricultura familiar e ação política para compor: a historicização de como são produzidas as práticas discursivas presentes nas relações familiares, de trabalho, espaços de ação e participação política no movimento social, nas relações consigo e com os outros; o mapeamento dos jogos de saber e poder e efeitos de subjetividade produzidos a partir das práticas, dos dispositivos.

A pesquisa seguiu uma perspectiva etnográfica, com a inserção e acompanhamento das atividades nos espaços da casa, da propriedade e do Movimento de Mulheres Trabalhadoras Rurais (MMTR), além da realização de entrevistas.

Participaram do estudo 18 mulheres com idades compreendidas entre os 30 e os 67 anos, das quais duas eram solteiras, com 31 e 42 anos de idade e não tinham filhos/as. Uma das participantes, com 59 anos, era viúva, e as demais eram casadas com um/uma, dois/duas, ou três filhos/as. À exceção, uma das participantes era casada e sem filhos/as; e uma participante com 67 anos e nove filhos/as. Todas as participantes se declararam agricultoras e eram participantes do MMTR, vinculado a Confederação Nacional dos Trabalhadores Rurais (CONTAG). (Vide tabela 1).
Tabela 1. Caracterização das Participantes

\begin{tabular}{lll}
\hline & Caracterização & N \\
\hline Sexo/Gênero & Feminino & 18 \\
Faixa etária & $30-36$ & 03 \\
& $42-47$ & 06 \\
& $53-59$ & 07 \\
Escolaridade & $65-67$ & 02 \\
& Ensino fundamental incompleto & 10 \\
& Ensino médio incompleto & 01 \\
Estado Civil & Ensino médio completo & 06 \\
& Não estudou & 01 \\
Número de filhos/as & Solteira & 02 \\
& Casada & 15 \\
& Viúva & 01 \\
& Sem filhos/as 01 a 02 filhos/as & 03 \\
Profissão & 03 filhos/as & 09 \\
Movimento social & 09 filhos/as & 05 \\
& Agricultora & 01 \\
& MMTR & 18 \\
\hline
\end{tabular}

As análises contemplaram o mapeamento das racionalidades imersas nas práticas associadas às especificidades da agricultura familiar da região noroeste do Estado do RS do Brasil, bem como a inserção no movimento de trabalhadoras rurais e a ação política daí decorrentes, associadas a um éthos agricultora.

A trajetória de vida, ligada à herança de terra, trabalho, família e participação política, narrada pelas mulheres, constituiu o fio condutor das reflexões e análises. As narrativas foram interseccionadas pelos marcadores de gênero, geração, classe e território. Nas discussões são apresentados fragmentos das relações e produções de gênero junto à família e ao trabalho; de geração, nas relações entre filhos/as, pai/mãe, sogro/ sogra, avô/avó; de classe, nos processos de escolarização, nos modos de trabalhar associados à agricultura familiar, à sucessão rural; e de território, nas especificidades dos contextos rurais, à apropriação de territórios que acionam modos de vida impressos à ruralidade, demarcados por uma circunscrição geográfica e também subjetiva. Esses marcadores são complementares e demarcam posicionamentos políticos.

Na sistematização e apresentação dos resultados, as discussões foram agrupadas a partir do tópico: "Os efeitos das experiências ligadas à agricultura familiar no sul do Brasil na produção de um éthos agricultora: herança de terra, trabalho e participação política", tendo as seguintes subdivisões: (i) Da sucessão familiar e a herança de terra, trabalho e família; (ii) Entre mulheres: mudanças e permanências nas práticas relacionadas com a casa, o trabalho e a participação política. 


\section{Os efeitos das experiências ligadas à agricultura familiar no sul do Brasil na produção de um éthos agricultora: herança de terra, trabalho e
participação política}

Acompanhar os efeitos das experiências no território da agricultura familiar implica problematizar as transformações sociais, políticas e econômicas de um cenário protagonizado por embates na luta por direitos e na luta pela terra.

No Brasil, a questão da terra foi e continua sendo motivo de embates e disputas, desde o período da colonização portuguesa (Alentejano, 2012; Martins, 1979/2010; Schneider, 2010). No final do século XIX as pessoas que imigravam e precisavam trabalhar para os latifundiários, pois não podiam comprá-las (Martins, 1979/2010).

Ainda, no contexto da imigração da época, José de Souza Martins (1979/2010) resgata os discursos políticos que faziam coro aos grandes fazendeiros na busca de imigrantes "morigerados, sóbrios e laboriosos" que a partir do "trabalho árduo, [poderiam] obter os recursos para comprar a terra necessária ao seu trabalho autônomo" (p. 240). Para o autor, entre as prioridades na seleção estavam os/as imigrantes casados/as, em relação aos/as solteiros/as, sendo que o perfil dos imigrantes pautava-se pelo cultivo das "principais virtudes consagradas na ética capitalista" (p. 240), os sofrimentos, as privações e o trabalho árduo seriam compensados com acesso à terra e à propriedade para produção agrícola em família.

A localização temporal dos discursos das mulheres participantes, deste estudo, se conectam aos anos iniciais do século XX, entre as décadas de 1930 e 1940 época de nascimento de seus genitores -, as décadas de 1960 e 1970, período de nascimento da maioria das participantes, e aos anos de 1990, período de casamento e nascimento dos/as filhos/as. Cada um desses períodos apresenta especificidades históricas, sociais, políticas e econômicas impressas nos modos de vida nas diferentes épocas.

No início do século passado, as condições de vida no campo eram permeadas por crises econômicas e miserabilidade. Na região noroeste do Estado do RS, as localidades de moradia e produção familiar situavam-se distantes dos centros urbanos e eram ocupadas pelos chamados deutschers, ou colonos de origem alemã. Ser deutscher, para os colonos, significava um posicionamento de superioridade quanto à ética de trabalho, em relação aos luso-brasileiros ou ítalo-brasileiros, mas também era sinônimo de "rural, simples, ingênuo e pouco familiarizado com as coisas do mundo urbano" (Woortmann, 2000, p. 217).

A aproximação dos anos de 1960 e 1970 mostra um período de grandes mudanças, com o advento da chamada Revolução Verde (Costa \& Carvalho 2012) expandindo uma agricultura baseada nos pacotes tecnológicos de mecanização, no uso intensivo de insumos químicos (fertilizantes e agrotóxicos) e de sementes geneticamente modificadas. A expulsão de grande contingente de trabalhadores e trabalhadoras do campo para a cidade foi consequência da diminuição dos postos de trabalho, da expansão dos latifúndios e da criação de empresas de alimentos em detrimento da produção familiar (Brumer, 2004). Esse processo se deu de forma diferente, em cada uma das regiões do Estado do RS. Diante de um novo modelo de produção que se tornava preponderante na política econômica brasileira, as famílias que permaneceram no campo demarca(ra)m resistência a esse modelo de produção em larga escala. A resistência se deu a partir dos espaços e instrumentos de organização autônomos, criados pelos/ as próprios/as trabalhadores/as, como associações de produtores rurais e sindicatos que formaram a base do que viria a ser o movimento social de mulheres trabalhadoras rurais, e emergiria com força no final dos anos 1980 (Cordeiro, 2004; Deere, 2004). Esse processo organizativo, também, pode ser entendido como parte de uma herança cultural de auto-organização comunitária, trazida pelos colonos alemães, baseada na ética do trabalho, na autonomia da unidade familiar, que garantia a infraestrutura necessária para a organização da vida em comunidade, como a criação das cooperativas de produção e comercialização de produtos, de crédito, de energia elétrica, em uma dinâmica associativa que supria a ausência do Estado como provedor de políticas públicas.

O resultado dessa cultura de auto-organização política será significativo para as lutas dos novos movimentos sociais do campo, que emergem no Brasil no contexto da democratização e se consolidam nas lutas dos anos 1990 e nos atuais, a partir da conquista e implementação de direitos na Constituição de 1988. Mesmo com essas conquistas, os anos que se seguiram foram de resistência a um período denominado de década neoliberal.

Assim, se nos anos 1980 a luta foi pela conquista de direitos, na década seguinte a luta foi pela implementação do que havia sido conquistado na legislação. A partir dos anos 2000 , inicia-se um novo cenário para as políticas públicas no meio rural com a ascensão de 
um novo governo que tem forte vínculo com as lutas e demandas dos movimentos sociais. O Brasil viveu um período inédito de criação de políticas públicas de incentivo através de programas voltados para a agricultura familiar. Todavia, isso não significou uma ruptura com o modelo dual existente na produção agrícola brasileira. E, a partir de 2016 , com a instauração de um cenário de instabilidade política e econômica, advindo de um governo neoliberal, se acirram, novamente, o processo de lutas para garantia e manutenção dos direitos.

Esse cenário mostra a manutenção de uma disputa desigual entre dois modelos de produção: agricultura familiar e agricultura em larga escala. A agricultura familiar é um modo de produção que utiliza a mão de obra dos membros da família como trabalhadores na execução e apropriação dos resultados das atividades do empreendimento (Paulilo 2004; Schneider, 2016). Agricultura familiar, mais do que um modelo de produção, se constitui como uma estratégia de resistência ao modo de produção capitalista em larga escala (Grisa, Gazolla, \& Schneider, 2010; Schneider, 2016).

As raízes da agricultura familiar estão imersas numa racionalidade camponesa (Paulilo, 2004; Tardin, 2012) no que se refere ao modo de vida e as influências no processo de trabalho. O uso da categoria "agricultura familiar" aparece nos documentos oficiais das políticas públicas com o Programa de Fortalecimento da Agricultura Familiar (Decreto n.1.946, 28 de junho de 1996) em meados dos anos 1990. Mas só em 2006 se estabelecem definições claras sobre a caracterização da agricultura familiar (Lei n. 11.326, 24 de julho de 2006). Em 2005, a agricultura familiar passa a integrar todos os documentos e negociações realizadas no âmbito da Organização Mundial do Comércio (OMC), fruto da mobilização dos países em desenvolvimento, incluindo o Brasil (Schneider, 2010, 2016).

Neste sentido, as narrativas de vida das mulheres deste estudo estão inseridas no contexto da agricultura familiar, imersas numa rede de conflitos e tensionamentos históricos no campo (leno, 2013) e até hoje não resolvidos. E, remetem as especificidades e a localização dos discursos associados as influencias étnicas e culturais advindas da colonização alemã, da agricultura familiar na região noroeste do RS e, também da participação social no MMTR.

\section{Da Sucessão Familiar e a Herança de Terra, Traba- Iho e Família}

Como visto, desde o início da colonização alemã, a família já se colocava como pré-condição para a posse da terra, sendo a emigração não um projeto individual, mas familiar. As situações precárias e as dificuldades enfrentadas durante a viagem pelos colonos alemães até à chegada às cidades brasileiras, significava a construção de um sonho inspirado nas comunidades germânicas. A presença de uma igreja, uma escola e terra para moradia e trabalho são marcas de um passado de "muito trabalho e nenhuma fartura" (Woortmann, 2000, p. 218).

Entre os efeitos dessas práticas nos modos de subjetivação associados à colonização alemã, podemos identificar: o trabalho em família como meio de alcançar um futuro melhor, permeado por racionalidades conectadas à terra e ao trabalho e a crença religiosa como suporte para vencer as inúmeras dificuldades enfrentadas pela família. A instituição família se insere como um valor tão significativo quanto a terra e o trabalho, e estão agrupados na categoria de agricultura familiar. Assim, a agricultura familiar produz uma síntese de um modo de vida atrelado à casa, à família e ao trabalho.

Neste contexto, a produção de uma narrativa de si "a gente é alemoa" se aproxima do resgate/ lembrança de uma origem étnica que traz consigo uma moral, uma cultura que prioriza o trabalho e os esforços daí empreendidos. O discurso "a gente é alemoa" produz o sujeito trabalhador, empreendedor, autônomo e cooperativado. A narrativa religiosa remete à necessidade do sacrifício no presente e a promessa de uma vida melhor no futuro. Essas práticas balizadoras de modos de viver e se posicionar, diante de si e dos outros, atuam na composição de um éthos agricultura. Éthos como um comportamento/posicionamento diante da vida, ligado a uma moral ascética expressa nas práticas relacionadas com a terra, trabalho e família. Foucault (2012c) se refere ao ascetismo como uma prática ascética "não no sentido de uma moral da renúncia, mas o exercício de si sobre si mesmo através do qual se procura se elaborar, se transformar e atingir um certo modo de ser" (p. 259).

As reverberações de uma moral ascética e as práticas que dela advêm estão enredadas às condições de possibilidade associada aos modos de vida impressos pelos princípios da autonomia individual, do empreendedorismo e da valorização do trabalho (Weber, 2002). Diz de uma modelagem de sujeito que resulta de um regime de verdade baseado no "espírito empreendedor" (Weber, 2002) e nas premissas de "quem poupa tem", "Deus ajuda quem trabalha" e de que é preciso "sacrifício para ser alguém na vida". Essa dinâmica está profundamente arraigada na cultura das comunidades 
rurais de origem alemã, com forte vinculação com a religião cristã, de raiz protestante.

Nas narrativas, as situações de pobreza e de escassez de recursos vivenciadas eram vistas como etapas da vida a serem superadas pelo próprio esforço, através do trabalho da terra que daria frutos e supriria as necessidades da família. Os valores e os preceitos morais associados à honra e ao cultivo dos "bons costumes" são relacionados com as práticas de governo de si (Foucault, 2012b) de modo que, no futuro próximo, se alcançasse um lugar de destaque na sociedade, e se pudesse "ser alguém na vida". Assim, imersos nas relações normativas e disciplinares no ambiente familiar e social, a "moral e os bons costumes", a valorização de "uma mulher direita", de "filhos obedientes" são valores reafirmados pelas práticas educativas formais e informais.

Essas práticas estavam voltadas para a disciplina, trabalho árduo, poupança, respeito pelas tradições, atravessadas por racionalidades reprodutoras de um sistema social normativo que previa a manutenção das hierarquias patriarcais e a divisão social e sexual do trabalho (Holzmann, 2006).

No território da agricultura familiar, as relações afetivas e familiares se mostram intrínsecas e interdependentes às relações de trabalho na unidade produtiva. A manutenção da normativa dos valores familiares é condição para a efetividade das relações laborais no empreendimento familiar. Na agricultura familiar a terra é espaço de vida, moradia e trabalho (Schneider, 2010; Wanderley, 2009). Da terra advém o sustento, fruto do trabalho.

A herança de terra, trabalho e família mostra-se naturalizada no discurso familiar. A participação em atividades laborais, a ajuda aos pais no cuidado com os animais e na colheita, se faz presente na vida das mulheres desde a infância. Para algumas mulheres, a chegada à vida adulta é narrada pela maior inserção em atividades laborais, remuneradas ou não, pelo enlace matrimonial e a constituição de uma nova família. Em alguns casos, a permanência das mulheres no campo aparece relacionada com o casamento.

Por sua vez, estudos mostram que a herança da terra prioriza a tradição familiar de manutenção da propriedade associada com o cuidado dos genitores, em detrimento das leis (Paulilo, 2004, 2009; Silva \& Schneider, 2010; Woortmann, 2000). Em cada família, se decide quem dentre os/as filhos/as assumirá a propriedade, passará a residir com os genitores e assumirá, por sua vez, o cuidado das pessoas idosas (Oliveira Jr. \&
Prado, 2013). No processo de inventário da terra, as filhas mulheres e os/as demais filhos/as vendem suas partes a quem ficou definido o direito de assumir a propriedade.

Ainda, se fazem presentes nas narrativas das mulheres participantes do estudo, a transmissão da propriedade da terra, tradicionalmente endereçada ao filho homem que passa a residir com a esposa e administrar a propriedade (Stropasolas, 2004): "Hoje moro com a minha família, o meu marido, minha filha e o meu sogro e minha sogra... a gente assumiu eles e pagamos os herdeiros, os filhos. Daí a gente pagou e ficou com tudo que tinha ali" (N.E.)

Análises, alicerçadas em gênero e geração, traçam problematizações sobre os modos como a sucessão rural acontece (Paulilo, 2004, 2009). Entre as leituras possíveis evidenciadas nas narrativas, pode ser destacado que a herança da terra ao filho significa, não necessariamente, a passagem da gestão da propriedade. Na maioria das vezes, a chefia da propriedade e as decisões sobre o que plantar, como investir os recursos e a divisão dos lucros da produção entre os membros da família permanecem nas mãos do patriarca. Esse modo de organização familiar denota um posicionamento de priorização dos interesses familiares, em detrimento dos projetos individuais. O projeto de vida narrado na agricultura familiar se constitui de modo coletivo.

Por sua vez, a permanência das mulheres no campo está vinculada ao casamento com um herdeiro da terra e passa a conviver na propriedade com o sogro e a sogra. Neste enredo, o reconhecimento da mulher como agricultora está relacionado com o casamento (Paulilo, 2000, 2004, 2009).

Nesta configuração familiar, à mulher é endereçada a responsabilidade como cuidadora dos/das idosos/as, além dos/as filhos/as, das pessoas com deficiência e demais pessoas que necessitem de ações de cuidado na família. A herança das práticas de cuidado, de responsabilização exclusiva das mulheres, contribui para a manutenção de racionalidades imersas numa lógica normativa e patriarcal. As normativas tradicionais de gênero destinadas às mulheres estão associadas às atividades reprodutivas ligadas à esfera privada (Holzmann, 2006), naturalizadas, transmitidas e mantidas de geração em geração.

O aumento da expectativa de vida da população repercute no aumento do número de horas dedicado ao cuidado com pessoas idosas, ainda invisibilizado no trabalho doméstico (Paulilo, 2000). Acrescidas, ao conjunto de atividades laborais exercidas pelas 
mulheres, dentro e fora de casa, as atividades como cuidadoras foram apontadas como produtoras de sobrecarga física e emocional: "Eu tinha uma vida sofrida... a sogra quando ela estava doente, ela ficou de cama, não podia mais caminhar... isso não foi nada fácil." (L.D.)

Diante do sofrimento explicitado pelas práticas de cuidado, não há por parte das mulheres uma reivindicação ou propositura de outras alternativas de organização do cuidado. O cuidado aparece como uma obrigação moral: "é obrigação dos filhos cuidarem dos pais idosos". Essas práticas são tomadas como um "trabalho" que precisa ser feito e, no registro cultural da família deve ser realizado pelas mulheres. No ciclo familiar, essa herança é endereçada também às novas gerações, como no caso de C.W., que cuidou do sogro e da sogra doentes e da cunhada com deficiência. Agora, aos 57 anos, sua família já se organizou para a sucessão rural, tendo apontado o filho que será responsável pelo cuidado dela e do marido.

Nas práticas de cuidado os discursos produzidos levam em conta que os filhos de hoje serão pais e os pais serão avós no futuro. De modo que, cada um faz sua parte para que possa receber o que lhe é de direito, ou seja, ser cuidado pela geração sucessora. A naturalização e transmissão dessas posições parece sinalizar a manutenção de relações de poder hierarquizadas, chefiadas por homens com maior idade cronológica na família. Esse fenômeno pode estar associado ao processo contemporâneo de saída das mulheres do campo, o que resulta na masculinização e no envelhecimento da população rural (Brumer, 2004).

A convivência cotidiana entre três gerações, numa mesma propriedade, ou numa mesma casa foi narrada como desafiadora e, por vezes, irradiadora de conflitos intergeracionais. Os diferentes costumes e modos de pensar, a criação dos/as filhos/as, a administração da casa e os recursos advindos do trabalho na propriedade evidenciam possíveis pontos de tensionamentos familiares.

V.B. é a mais jovem entre as participantes. Está há quatro meses casada e reside na mesma propriedade com o pai e mãe do marido, mas em casas separadas. Segundo ela, se morassem juntos "acho que nós não estaríamos ainda casados." Relata entre as dificuldades enfrentadas para se inserir na "nova família", o fato de não ser moradora da cidade e também não ser "alemoa" e não falar a língua da família. V.B. salienta que em casa todos falam em alemão e quem vem de fora precisa aprender a língua de casa. "A minha dificuldade foi a língua alemã, né? (...) E é bem difícil inclusive... Eles falam mais alemão, eles têm dificuldade de falar em português..."

A integração de culturas diferentes, modos de pensar, sentir e se relacionar com o mundo e com as pessoas são desafios a serem enfrentados. V.B. narra dificuldades na convivência quando não se fala a mesma língua e se tem expressa no corpo uma cor da pele com muito mais melanina. No imaginário das famílias, há uma clara separação entre o "povo de origem alemã" e o "povo brasileiro" cercado de estereótipos, de ambas as partes, em relação às diferentes culturas. Na região, o "povo alemão" é caracterizado como "trabalhador", "pontual", "teimoso", "rígido" "de baixar a cabeça e fazer as coisas do seu jeito". O "jeito fechado" pode ser associado, entre outras coisas, às dificuldades em manifestar seus sentimentos e/ou dificuldades em manifestar gestos de carinho e afeto, como refere (I.H.):

ele [marido]... é uma pessoa muito boa... ele não é carinhoso... isto ele não faz, mas assim não tem reclamação, não tem pessoa melhor... para dizer a verdade, esses quarenta e um anos ele nunca, não disse tu é querida, ou tu fez uma coisa bonita. Eu vejo que ele gosta, mas ele não diz... ele é uma pessoa muito boa... só que isso é um pouco assim... faz falta".

Aos 65 anos e casada há mais de quatro décadas, I.H. ao fazer menção às dificuldades sentidas no relacionamento com o marido, parece quase pedir desculpas por expressar, por vezes, seu descontentamento com algumas das posturas dele. O marido "não tem reclamação... ele é uma pessoa muito boa... não tem pessoa melhor"; as queixas se voltam às dificuldades de expressar afeto, que a fazem sofrer, mas não acredita que a situação possa melhorar depois de tantos anos juntos. As dificuldades de expressar afetos e dizer o que sente, também é de I.H. ao naturalizar uma herança cultural, ao ser subjetivada como "alemoa". Não se trata de determinismo, mas de possíveis cristalizações das condições de possibilidade que passaram de geração em geração, sem serem questionadas até então.

V.B., por sua vez, narra relações próximas com seus pais e a facilidade de expressar afetos, "a relação com meus pais é ótima... qualquer problema que tem... se discute o problema, tenta ajudar, sabe?" Ela relaciona sua inserção e participação nas atividades de ação política com um melhor preparo para lidar com as situações difíceis: "devido a esse convívio com sindicato e várias experiências de pessoas né... parece que ... me 
preparou muito... para enfrentar assim, buscar novos caminhos." E é um pouco de sua herança cultural que ela procura levar para a relação com o marido.

Por sua vez, o apoio do marido a auxilia no processo de inserção na cultura em família, tanto no que se refere a conseguir se expressar no idioma familiar, como também na organização do processo de trabalho. V.B. sinaliza que, mesmo não concordando totalmente com a administração dos genitores do marido, as mudanças precisam ser aos poucos. Ela avalia que o sogro e a sogra são jovens e há previsão de longa convivência entre eles, cabe-lhe assim, a negociação para evitar desentendimentos: "Cada um tem seu serviço... [ou] todo mundo vai junto e faz, ou uma fica em casa e faz o almoço e outra vai ajudar" Questionada se essa organização do trabalho funciona, ela responde: "Funciona, tem que funcionar, né? Por que não adianta fazer uma coisa, outro puxar para lá não dá certo."

Entre I.H. e V.B. se poderiam tecer aproximações e distanciamentos entre os posicionamentos adotados nas relações afetivo familiares e laborais. Tendo em conta, uma diferença de idade entre elas de 35 anos, ao se casarem ambas passam a residir com o marido na propriedade da família paterna. Ainda, se faz presente no discurso a ideia de um casamento duradouro, "para a vida toda."

O trabalho permanece sendo uma obrigação de todos os membros da família, não se tendo muitas escolhas. Mas, por outro lado, há detalhes que parecem levantar possíveis questionamentos e talvez fissuras nas normativas tradicionais de gênero. É o que sinaliza V.B., ao se manifestar e expressar o que pensa e sente em relação às suas escolhas, marcando diferenças ao se propor a conversar com o marido e negociar os afazeres de trabalho de dentro e fora de casa "tu não é empregado de ninguém na realidade, se eu posso ajudar lá fora... [ele] pode me ajudar ali dentro." Esse posicionamento "reivindicativo" sinaliza o tensionamento de atribuições naturalizadas de gênero, no entanto, as práticas ainda são nomeadas como caráter de "ajuda" e divididas entre o que é "trabalho de mulher" e o que é "trabalho de homem." Mesmo de forma lenta, se pode vislumbrar alguns movimentos de mudanças de posições.

\section{Entre Mulheres: Mudanças e Permanências nas Práticas Relacionadas com a Casa, o Trabalho e a Participação Política}

Como visto, as narrativas expressam relações familiares pautadas em posições tradicionais de gênero. As pessoas mais velhas, em geral, possuem voz mais ativa, orientando a manutenção de costumes e valores morais no ambiente familiar. Para as mulheres, entre as situações mais conflituosas parece estar o relacionamento com a sogra: "Eu sofri bastante sabe, ali com minha sogra porque ela também veio de uma família em que mulher é para ficar em casa" (S.E.). Ou ainda:

Eu disse assim, para o meu marido, eu poderia estar lá até hoje. Mas daí depois eu optei porque a vovó [sogra] sempre foi contra né (...) ela tem alergia ao sindicato. Como eu não ia deixar os filhos para ela criar, né... daí eu parei [de atuar no sindicato e no MMTR] (I.M.).

Tanto no caso de S.E. como de I.M., a sogra aparece como a guardiã da moral e dos costumes da família. A ela cabe zelar pelo cumprimento de um papel normativo de gênero, dentro do que seria esperado para uma "boa esposa" e uma "boa mãe de família". A militância no sindicato e no MMTR se distancia do cumprimento das atividades desempenhadas por uma boa "dona de casa", "esposa" e "mãe". Nas narrativas os conflitos geracionais parecem ocupar maior visibilidade do que os conjugais. Os maiores tensionamentos estão relacionados com a saída de casa e a participação no movimento social.

Nas narrativas de mulheres com idades entre os 40 e 50 anos, ambos, marido e mulher, aparecem inseridos nas atividades de trabalho na propriedade (nos espaços fora de casa) e nos afazeres domésticos (no espaço privado do lar). As narrativas parecem tecer relações mais igualitárias de gênero. No entanto, a presença de duas mulheres "dentro de casa" (a mãe e a esposa) aparece como uma justificativa possível da não necessidade de ajuda do marido nas atividades dentro de casa. A partir das narrativas das mulheres participantes, o conjunto de valores e ideias associadas à terra, ao trabalho e à família, parece dar sinais de mudanças. Na geração anterior, a permanência no campo estava associada à organização familiar para a realização de um bom trabalho que tivesse como resultado a melhoria da condição econômica e a garantia de um futuro melhor. Nas narrativas, as mulheres apontam melhorias na condição econômica da família, nos últimos anos, em relação à família de origem ou à geração anterior. Entre elas estão: a ampliação do tamanho da unidade produtiva, a casa mais ampla e confortável, o incremento de tecnologia nas atividades agrícolas e/ou na criação e ordenha do gado leiteiro. Sendo possível afirmar que "hoje já está bem melhor do que quando nós começamos, sabe" (N.E.).

Os esforços familiares estão direcionados à formação dos/as filhos/as no intuito de deixarem como herança 
condições de uma vida melhor: "O que eu podia dar para os meus filhos eu dei...nós nem tínhamos luz elétrica" (C.W.). A prioridade das famílias está na educação dos/as filhos/as, e não mais na formação pelo trabalho: "hoje o estudo é o primeiro, antigamente não era" (O.H.).

A oportunidade de avanço na escolarização é vista como uma possibilidade de abertura às novas escolhas: "o meu menino, ele é um guri assim, ele não tem assim muita [vontade] de trabalhar assim na lavoura... ele é mais de estudar" (N.B.). O estudo é tomado como transformação do que se é, e em alguma medida reflete um distanciamento da ideia de trabalhadora rural "sem conhecimento". A herança dos pais não é mais só da terra, mas também a formação técnica para se manter na terra. E ainda, como possibilidade de escolha entre permanecer ou sair do campo.

Embora se tenha consciência de que, quanto maior a escolarização, menores são as chances de permanência no campo, há uma preocupação de como ficará a vida no campo no futuro. Ao mesmo tempo, há um reconhecimento de que ficar na agricultura precisa ser uma escolha e não mais uma necessidade de sobrevivência, como num passado recente: "hoje para ser agricultora, para levar essa vida tem que gostar..." (N.B.).

Restam muitas dúvidas em como será o futuro, como e quem fará a sucessão rural, quem continuará os negócios da família e as lidas do campo. A situação gera angústia e ansiedade, de modo que a família procura se organizar para tentar manter os/as filhos/as próximos/as, mas sabe que não há garantias de que permaneçam no campo, como refere (I.M.): "Nós estamos comprando terra no Fazendo Agroindústria aqui, para ver se a gente deixa os filhos por perto [...] Ninguém vai ficar no interior se não tiver dinheiro."

Entre as muitas incertezas, está o cenário de desvalorização da agricultura e as dificuldades para se manter financeiramente no campo. Nas narrativas das mulheres fica evidenciada a prioridade de que os/as filhos/as possam avaliar o que parece ser melhor para suas vidas e escolher: "Hoje já o próprio pai está vendo que não tem muito futuro na agricultura [...] a agricultura é umas das profissões que mais se sofre e que é menos valorizada." (N.B.).

Mesmo com o reconhecimento da melhoria da condição de vida, ainda o trabalho no campo é considerado pesado em relação a outras atividades: "não tem comparação, eu acho que hoje já ninguém quer ficar em casa mais, os filhos veem que é muito serviço que ainda nós temos. Mas eu acho pouco se comparado com o que trabalhamos antigamente" (O.H.).

Nas mudanças geracionais se percebe a permanência e a continuidade de uma herança marcada pelo discurso baseado na moral ascética de valorização do trabalho. De algum modo, se pode pensar o desejo de um maior grau de instrução inserido na lógica das exigências de uma sociedade capitalista moderna em constantes transformações. E que, de certo modo, produz distanciamento da valorização de saberes tradicionais e processos locais.

A participação política, para algumas mulheres, foi apontada como um legado familiar, sendo transmitida de mãe para filha. A participação no movimento social se relaciona ao esforço empreendido para alcançar mudanças relacionadas aos modos de vida produtores de opressão e sofrimento. No MMTR, a organização e a formulação de pautas coletivas se dão na expectativa de fortalecer discussões e práticas que venham resultar numa melhoria de vida para si mesma, como também, para a família e comunidade em que se vive. A participação pode ser correlacionada a uma herança familiar, uma passagem de modos de se posicionar no espaço da comunidade: "desde muito cedo comecei a participar e a atuar na minha comunidade... fiz leituras na igreja... o meu pai já era diretoria da comunidade, e a minha mãe também sempre atuava no coral da comunidade...." (G.H.)

A herança da participação política no MMTR é expressa com orgulho na narrativa das participantes. A.P., filha de uma das fundadoras do MMTR de seu município de moradia, se sente grata em poder dar continuidade ao trabalho iniciado pela mãe e poder ir além. A.P. fala com satisfação da trajetória de "sacrifícios" vivenciada pela mãe e se emociona ao se posicionar como herdeira do legado de lutas por direitos no movimento de mulheres trabalhadoras rurais. Ela é uma das lideranças jovens do MMTR na região, solteira, vive intensamente as atividades do movimento social, e refere não fazer planos de casamento.

O espelhamento em outras mulheres que vieram antes, que iniciaram o processo de luta das mulheres, neste caso as próprias mães, servem de inspiração para a continuidade e ampliação do processo de luta em prol de direitos: "eu sei que o sonho dela [mãe] muitas vezes foi de viajar a Brasília né, ela não conseguiu, mas hoje eu estou indo" (A.P.).

A herança aqui pode ser pensada como sementes de um "vir a ser", sendo a herança de participação política tomada como um dispositivo de subjetivação 
(Foucault, 1979/1995). O que implica pensar a dimensão participativa a partir de uma rede de relações imbricada ao contexto histórico e cultural, à singularidade das histórias de vida, à organização de pautas coletivas, e, assim, aos jogos de forças imersos nas relações estabelecidas dentro e fora do movimento de mulheres (Maciazeki-Gomes, Nogueira, Vázquez, \& Toneli, 2016).

A participação no movimento social, expresso nas narrativas das mulheres, possibilitou o questionamento de lugares pré-estabelecidos às mulheres nas relações familiares e de trabalho. A narração de cenas e imagens de ocupação das mulheres dos espaços públicos e do exercício da oratória parece fazer parte de uma performatividade (Butler, 2015) de si em relação aos outros, como exercício de uma ação política: "Hoje nesse lugar de coordenação... tento passar para as mulheres... que elas têm capacidade e são capazes!"(S.E.). A trajetória de luta trilhada pelas mães e agora pelas filhas no movimento de mulheres produziu um deslocamento das posições das mulheres como donas de casa e cuidadoras, para além de uma herança associada ao casamento e à constituição de uma prole. E contribuiu, ainda, para o reconhecimento e nomeação da mulher como trabalhadora rural (Cordeiro, 2004). Os avanços são reconhecidos pelas mulheres, bem como os desafios a serem superados. Entre eles estão os modos de expandir essas conquistas e posicionamentos, também, para as relações domésticas (Ávila \& Ferreira, 2014; Venturini \& Godinho, 2013).

Neste contexto, os efeitos da experiência da herança da participação política puderam ser vistos nas práticas cotidianas, com uma maior inserção e participação das mulheres em espaços públicos e decisórios, bem como em espaços familiares, ligados à casa e à propriedade. Como um processo que segue seu fluxo, entre avanços e tensionamentos, as mulheres vêm tecendo críticas aos discursos instituídos e naturalizados, ligados à dona de casa, que só cuida do marido, da casa e dos/ as filhos/as, como um discurso vigente e dominante presente nas práticas sociais. A inserção e participação em atividades do MMTR vêm produzindo aberturas para outros tantos posicionamentos associados a visões críticas das atribuições normativas de gênero.

\section{Considerações finais}

Neste estudo, a produção de um éthos agricultora estabelece uma estreita relação com a terra, como depositária das esperanças de um futuro melhor para as famílias através do trabalho. Conecta-se ao processo de luta e das conquistas oriundas do movimento social de mulheres trabalhadoras rurais, em prol de melhorias das condições de vida no campo, da ampliação de incentivos para a agricultura familiar, da luta pelo acesso à saúde e educação. $\mathrm{E}$, também, pelo repensar as tradicionais relações de gênero.

Salienta-se que este estudo apresenta problematizações analisadas à luz das condições de possibilidades inerentes à contingência de um tempo social circunscrito e politicamente situado. Ao não prever a generalização dos dados produzidos, vem contribuir com o estudo das especificidades étnico-regionais, da ação política e dos modos de subjetivação relacionados com os efeitos das práticas produzidas no contexto agricultura familiar na região noroeste do Estado do RS do Brasil.

A herança transmitida, de geração em geração, reporta a problematizações acerca das posições historicamente ocupadas pelas mulheres nas relações familiares e de trabalho. As participantes do movimento de mulheres trabalhadoras rurais, da nova geração, parecem vir reforçando os questionamentos diante das racionalidades normativas impressas pelo patriarcado e influências religiosas. Em alguma medida, buscam equilibrar os projetos familiares com seus projetos de vida individuais/pessoais, não sem prescindir de conflitos, tensionamentos e disputas de poder. Essas questões configuram relações mais complexas e indicam a necessidade de estudos futuros que possam aprofundar essas discussões.

A participação no movimento social de trabalhadoras rurais tem produzido efeitos no fortalecimento do processo de luta por direitos e, também, no sentimento de pertencimento aos modos de vida rurais. Os efeitos da ação política contribuem para a produção de estratégias de resistência e criação, uma vez que potencializam posicionamentos críticos diante de modos de vida associados às atribuições normativas de gênero e, ao mesmo tempo, contribuem para abertura de modos de vida outros. Ainda, são muitos os desafios a serem enfrentados, mas as mulheres não se deixam aquietar, seguem em movimento questionando a herança recebida e reinventando o éthos agricultora. Leva em conta a partir dos modos de vida na agricultura familiar.

\section{Referências}

Alentejano, P. (2012). Terra. In R. S. Caldart, I. B. Pereira, P. Alentejano, \& G. Frigotto (Orgs.), Dicionário da educação do campo (pp. 742-745) Rio de Janeiro, São Paulo: Escola Politécnica de Saúde Joaquim Venâncio, Expressão Popular. 
Ávila, M. B., \& Ferreira, V. (2014). Trabalho remunerado e trabalho doméstico no cotidiano das mulheres. Recife, SOS Corpo. Recuperado de http://agenciapatriciagalvao.org.br/wp-content/uploads/2014/07/ livro_trabalho_versaoonline.pdf

Brumer, A. (2004). Gênero e agricultura: a situação da mulher na agricultura do Rio Grande do Sul. Revista Estudos Feministas, 12(1), 205-227. doi: 10.1590/S0104-026X2004000100011

Butler, J. (1998). Fundamentos contingentes: feminismos e a questão da "pós-modernismo". Cadernos Pagú, 11, 11-42. Recuperado de https://periodicos.sbu.unicamp.br/ojs/index.php/cadpagu/article/ view/8634457/2381

Butler, J. (2015). Problemas de gênero. Feminismo e subversão da identidade. Rio de Janeiro: Civilização Brasileira.

Castro, E. (2016). Vocabulário de Foucault. Um percurso pelos temas, conceitos e autores (I. M. Xavier, Trad.). Belo Horizonte: Autentica.

Cordeiro, R. L. M. (2004). Além das secas e das chuvas. O uso da nomeação da mulher trabalhadora rural no sertão central de Pernambuco (Tese de Doutorado, Pontifícia Universidade Católica de São Paulo, São Paulo).

Costa, F. A., \& Carvalho, H. M. (2012). Campesinato. In R. S. Caldart, I. B. Pereira, P. Alentejano, \& G. Frigotto (Orgs.), Dicionário da Educação do campo (pp.115-122). Rio de Janeiro, São Paulo: Escola Politécnica de Saúde Joaquim Venâncio, Expressão Popular.

Decreto n. 1. 946. (1996, 28 de junho). Cria o Programa Nacional de Fortalecimento da Agricultura Familiar - PRONAF. Brasília, DF: Presidência da República. Recuperado de: http://www.planalto.gov. br/ccivil_03/decreto/D1946.htmimpressao.htm

Deere, C. D. (2004). Os direitos da mulher à terra e os movimentos sociais rurais na reforma agrária brasileira. Revista Estudos Feministas, 12(1), 175-204. doi: 10.1590/S0104-026X2004000100010

Fernández, A. M. (2008). Política y Subjetividad-asambleas barriales y fábricas recuperadas. Buenos Aires: Biblos.

Foucault, M. (1995). Nietzsche a Genealogia e a história. In R. Machado (Org.), Microfísica do Poder (pp. 15-38, R. Machado Trad.). Rio de Janeiro: Ed. Graal. (Obra original publicada em 1979)

Foucault, M. (2012a). Governamentalidade. In Ditos \& Escritos IV. Estratégia, saber e poder (pp. 275-298). Rio de Janeiro: Forense Universitária.

Foucault, M. (2012b). Os intelectuais e o poder. In Ditos \& Escritos IV. Estratégia, saber e poder (pp. 36-45). Rio de Janeiro: Forense Universitária.

Foucault, M. (2012c). Política e ética uma entrevista. In Ditos \& Escritos V. Ética, Sexualidade e Política (pp. 212-218). Rio de Janeiro: Forense Universitária

Foucault, M. (2012d). Foucault. In Ditos \& Escritos V. Ética, sexualidade e política, (pp. 228-233). Rio de Janeiro: Forense Universitária.

Foucault, M. (2013). As Heterotopias. In Os corpos utópicos e as heterotopias (S. Muchail Trad.) São Paulo: n-1 ed.

Grisa, C., Gazolla, M., \& Schneider, S. (2010). A "produção invisível" na agricultura familiar: autoconsumo, segurança alimentar e políticas públicas de desenvolvimento rural. Agroalimentaria, 16(31), 65-79. Recuperado de http://www.saber.ula.ve/handle/123456789/32254

Holzmann, L.(2006). Divisão sexual do trabalho.InA.D.Cattani \& L. Holzmann (Orgs.), Dicionário de Trabalho e Tecnologia (1를. ed., pp.103-106). Porto Alegre: UFRGS.

leno, G. (2013). Prefácio. In J. Leite \& M. Dimenstein (Orgs.), Psicologia e contextos rurais (pp. 13-18). Natal: EDUFRN.
Lein. 11.326, de 24 de julho de 2006. (2006, 24 de julho). Estabelece as diretrizes para formulação da Política Nacional da Agricultura Familiar e Empreendimentos Familiares Rurais. Diário Oficial da União, seção 1. Recuperado de http://www.planalto.gov.br/ccivil_03/_ato20042006/2006/lei/l11326.htm

Maciazeki-Gomes, R. C. (2017). Narrativas de si em movimento Uma genealogia da ação política de mulheres trabalhadoras rurais do sul do Brasil. (Tese de Doutorado, Universidade do Porto, Porto, Portugal). Recuperado de https://repositorio.ufsc.br/xmlui/ handle/123456789/180436

Maciazeki-Gomes, R. C., Nogueira, C., \& Toneli, M. J. F. (2016). Mulheres em contextos rurais: um mapeamento sobre gênero e ruralidade. Psicologia \& Sociedade, 28(1), 115-124. doi: 10.1590/1807-03102015v28n1p115

Maciazeki-Gomes, R. C., Nogueira, C., Vázquez, C., \& Toneli, M. J. F. (2016). Participação política e subjetividade - Narrativas de vida de trabalhadoras rurais do sul do Brasil. Psico, 47(2), 148-158. Recuperado de http://revistaseletronicas.pucrs.br/revistapsico/ojs/ index.php/revistapsico/article/view/21993

Martins, J. S. (2010). O cativeiro da terra (9ª ed.) São Paulo: Contexto. (Obra original publicada em 1979)

Nogueira, C. (2013). A teoria da interseccionalidade nos estudos de gênero sexualidades: condições de produção de "novas possibilidades" no projeto de uma psicologia feminista crítica. In A. V. Zanella, A. L. Brizola, \& M. Gesser (Orgs.), Práticas sociais, políticas públicas e direitos humanos (pp. 227-248). Florianópolis: ABRAPSO.

Oliveira Jr., O., \& Prado, M. A. M. (2013). A categoria juventude em contextos rurais: 0 dilema da migração. In J. F. Leite \& M. Dimeinstein (Orgs.), Psicologia e contextos rurais (pp. 58-88). Natal: EDUFRN.

Ortega, F. (1999). A amizade e estética da existência em Foucault. Rio de Janeiro: Graal.

Paulilo, M. I. S. (2000). Movimento de mulheres agricultoras: terra e matrimônio. Cadernos de Pesquisa, 21, 1-17. Recuperado de https://naf.ufsc.br/files/2010/08/mma1.pdf

Paulilo, M. I. S. (2004). Trabalho familiar uma categoria esquecida de análise. Estudos Feministas, 12(1), 229-252. doi: 10.1590/ S0104-026X2004000100012

Paulilo, M. I. S. (2009). Movimento das mulheres agricultoras e os muitos sentidos da "igualdade de gênero". In B. M. Fernandes, L. S. Medeiros, \& M. I. Paulilo (Orgs.), Lutas camponesas contemporâneas: condições, dilemas e conquistas: a diversidade das formas das lutas no campo (2 $2^{\underline{a}}$ ed., pp. 179-202). São Paulo: UNESP, Brasília: NEAD.

Schneider, S. (2010). Reflexões sobre diversidade e diversificação. Agricultura, formas familiares e desenvolvimento rural. Ruris, 4(1) 85-131. Recuperado de https://www.ifch.unicamp.br/ojs/index.php/ ruris/article/view/708

Schneider, S. (2016). A Presença e as potencialidades da Agricultura Familiar na América Latina e no Caribe. Redes, 21(3), 11-33. doi: 10.17058/redes.v21i3.8390

Scott, P. (2010). Gerações e famílias: polissemia, mudanças históricas e mobilidade. Revista Sociedade e Estado, 25(2), 251-284. doi: 10.1590/S0102-69922010000200006

Silva, C. B. C., \& Schneider, S. (2010). Gênero, trabalho rural e pluriatividade. In P. Scott, R. Cordeiro, \& M. Menezes (Orgs.), Gênero e geração em contextos rurais (pp. 183-207). Florianópolis: Mulheres.

Stropasolas, V. L. (2004). O valor (do) casamento na agricultura familiar. Revista Estudos Feministas, 12(1), 253-267. doi: 10.1590/ S0104-026X2004000100013 
Tardin, J. M. (2012). Cultura Camponesa. In R. S. Caldart, I. B. Pereira, P. Alentejano, \& G. Frigotto (Orgs.), Dicionário da Educação do campo (pp.180-192). Rio de Janeiro, São Paulo: Escola Politécnica de Saúde Joaquim Venâncio, Expressão Popular.

Venturini, G., \& Godinho, T. (Orgs.) (2013). Mulheres brasileiras e gênero nos espaços público e privado: uma década de mudanças na opinião pública. São Paulo: Perseu Abramo.
Wanderley, M. N. B.(2009). O mundo rural como um espaço de vida. Porto Alegre: EdUFRGS.

Weber, M. (2002). A estética protestante o espírito do capitalismo. São Paulo: Martin Claret.

Woortmann, E. F. (2000). Identidades e memórias entre teuto-brasileiros: os dois lados do atlântico. Horizontes Antropológicos, 6(14), 205-238. doi: 10.1590/S0104-71832000001400009

Rita de Cássia Maciazeki-Gomes, Doutora em Psicologia pela Faculdade de Psicologia e de Ciências da Educação da Universidade do Porto (FPCEUP), em cotutela com a Universidade Federal de Santa

Catarina (UFSC), Pós-Doutora em Saúde Coletiva na Universidade

Federal do Rio Grande do Sul (UFRGS), é Professora adjunta

na Universidade Federal do Rio Grande (FURG). Endereço para correspondência: Universidade Federal do Rio Grande, Instituto de Ciências Humanas e Informação, Curso de Psicologia. Av. Itália, km 8 - Carreiros, CEP 90.620110 - Rio Grande, RS - Brasil. Telefone: (53) 3293.5123. Email: ritamaciazeki@gmail.com

Maria Juracy Filgueiras Toneli, Doutora em Psicologia Escolar e do Desenvolvimento Humano pela Universidade de São Paulo (USP),

Pós-doutora em Psicologia Social pela Universidade Federal de Minas Gerais (UFMG) e Universidade do Minho (UM),

é Professora titular do Programa de Pós-graduação em Psicologia da Universidade Federal de Santa Catarina (UFSC). Email juracy.toneli@gmail.com

Conceição Nogueira, Doutora em Psicologia Social na Universidade do Minho (UM), é Professora associada na Faculdade de Psicologia e de Ciências da Educação da Universidade do Porto (FPCEUP). Email: cnogueira@fpce.up.pt

Rita Grave, Mestre em Psicologia na Faculdade de Psicologia e de Ciências da Educação da Universidade do Porto (FPCEUP), é doutoranda em Psicologia na Faculdade de Psicologia e de Ciências da Educação da Universidade do Porto (FPCEUP). Email: anaritaguerragrave@gmail.com

Recebido em 27.jun.17 Revisado em 11.jul.19 Aceito em 29.nov.19 